\title{
Sir James Y Simpson and London's "conservative and so curiously prejudiced" Dr Ramsbotham
}

\author{
MANFRED WASERMAN
}

The history of medicine division of the National Library of Medicine has in its manuscripts collection a body of correspondence that vividly describes the strong views held by James $\mathrm{Y}$ Simpson in espousing the use of obstetric anaesthesia. The collection consists of 31 letters written by Simpson, mostly from Edinburgh, to the London obstetrician Francis Henry Ramsbotham during the years 1844-53 (many of them composed at the bedside of women about to be delivered), drafts or copies of 15 letters sent to Simpson by Dr Ramsbotham, and several other holographs addressed to Ramsbotham. Despite the unfavourable circumstances under which Simpson wrote many of his letters and the poor legibility of the drafts and copies, the research condition of the material on the whole is surprisingly satisfactory.

The theme of the collection is the use of chloroform anaesthesia in childbirth. Surgical anaesthesia, ether, was discovered in the United States and first publicly demonstrated by William T G Morton at the Massachusetts General Hospital in October 1846; it was used first in obstetrics by Simpson in January 1847. Dissatisfied with many of the properties of ether-it was bulky and inflammable, induction was slow, and the lightly anaesthetised patient was liable to vomit-Simpson sought an alternative and soon discovered the anaesthetic properties of chloroform. ${ }^{1}$ In November 1847 Simpson introduced chloroform anaesthesia in obstetrics, and the practice spread quickly in Scotland. In England, however, its acceptance was slower, and clearly evident throughout this collection of correspondence is Simpson's message that London medicine is unreasonably conservative and distantly behind the more advanced practices of Scotland. In fact, in his letter to Ramsbotham dated 1 December 1846-even before the subject of obstetric anaesthesia had

\footnotetext{
History of Medicine Division, National Library of Medicine, Bethesda, Maryland 20209, USA

MANFRED WASERMAN, MA, MS, curator of modern manuscripts
}

become an issue-Simpson, in his straightforward manner, suggests that London therapeutics may be somewhat slack:

"I wish you would come ... and see how much the unimpregnated uterus can stand in the way of treatment in Scotland, without hysteria or other ills. ... I often think of you getting such a fright with leeches. But I am sure of one thing. I would prove to you all your fears on the care of local treatment to be unfounded."*

Foremost, however, the Simpson letters are concerned with the abolition of unnecessary suffering. It was "for the sake of your tortured woman" that Dr Simpson pleaded for the use of anaesthesia in childbirth.

The story of Simpson's discovery of chloroform anaesthesia, and the medical, religious, and moral objections and controversies that are part of its history, has been told many times. And a fair number of biographies of Sir James have also been published. ${ }^{2}$ Many honours had come to Simpson before he died in 1870 , aged 58 , and to one biographer the only physician in the modern era whose fame and influence during his lifetime approached Simpson's in magnitude was Herman Boerhaave. ${ }^{3}$ In 1847 Simpson was appointed one of Her Majesty's physicians for Scotland, and in 1856 he received the Monthyon prize from the French Academy of Sciences for "most important benefits done to humanity." In 1886 he received a baronetcy, the first given to a physician practising in Scotland. Still, the development of anaesthesia was by no means Simpson's sole achievement. His contributions to gynaecology and obstetrics were important, and only because of his great accomplishment with chloroform has his work in these areas received less notice. For relaxation, Simpson particularly enjoyed the subject of archaeology, on which he published more than a dozen papers.

Compared to Simpson, we have relatively little information about Francis Henry Ramsbotham. His father, John Ramsbotham, was a physician who enjoyed a large obstetric practice in East London. Francis was born in 1801, making

*When necessary for the sake of clarity punctuation and paragraph structure have been changed in quoted material. 
him 10 years Simpson's senior, and received his medical education at the London Hospital and at Edinburgh University, where he graduated $M D$ in 1822 . He was later appointed obstetric physician and lecturer on obstetric and forensic medicine at the London Hospital, as well as Physician to the Royal Maternity Charity. Ramsbotham's major contribution to medical literature was his textbook, The Principles and Practice of Obstetric Medicine and Surgery, in Reference to the Process of Parturition, first published in 1841. An impressive work with magnificent illustrations, the book eventually appeared in five editions. In Simpson's letter of 1 October 1844 -the first letter in this collection-Simpson refers to the volume and tells Dr Ramsbotham: ". . . yours is the best practical work, [Edward] Rigby's the best theoretical one." For many years Ramsbotham's "large practice and high repute ... made his name a household practice," but his continued opposition to the use of chloroform eventually brought about a decline in his "professional prospects." 4 Simpson's knowledgeable opinion was that Dr Ramsbotham had "seen in midwifery more rare cases than any man I know." "5

Exactly when Simpson and Ramsbotham became acquainted is not clear, but from the first letter in the collection it is obvious that this was not their initial communication. An examination of the Simpson biographies, however, has shown no mention of Ramsbotham's name, and a survey of likely Simpson manuscript repositories in Great Britain and the United States has uncovered very little additional extant correspondence between these two physicians. Despite their failure to agree on the merits of administering chloroform anaesthesia, and despite the occasional exchange of some ruffling language, it seems that $\mathrm{Dr}$ Simpson and Dr Ramsbotham were on very friendly terms and had high professional esteem for each other.

Unlike Huxley's role with Darwin, Simpson was his own Victorian bulldog. He often declared that if he found the opposition to the use of chloroform in midwifery too powerful to conquer alone, he would finally overcome it by creating a state of public opinion on the subject that would compel the profession to adopt his methods. ${ }^{6}$ In this group of letters, originally preserved by Dr Ramsbotham, Simpson's strong and inspiring personality is evident. It is not the object here to transcribe the complete collection, nor necessarily any of the letters in their entirety. All of the material pertains, generally, to obstetric procedures, to specific cases, or to various aspects of the controversy over the use of anaesthesia. Rather, the intention is to convey, in Simpson's own words, some of his unpublished views on the conservative position of London physicians, as personified by Dr Ramsbotham, concerning the use of chloroform in childbirth.

Simpson to Ramsbotham, 26 February 1847

"Have you tried the ether yet? The more I see of it, the more I feel convinced we shall all yet use it in common cases, even of labour."

Ramsbotham to Simpson, 12 March 1847

"Accept my best thanks for your paper on the inhalation of ether. I have not heard of any cases lately in which it has been used in our department here."?

Simpson to Ramsbotham, 1 May 1847

"I am etherising all my obstetric cases, the ladies all demand it here. Nothing but good results here."

10 September 1847

"I am using ether regularly in my midwifery practice and have no doubt whatever your grandchildren and mine will do so and wonder at us overcoming and not relieving human agony when we had the power and the means of doing it. As to bad results I have seen none."

\section{January 1848}

"A few weeks ago I had a communication from Vienna telling me that formerly 70 in every 100 women delivered in the Hospital died of puerperal disease. They delivered new patients in beds still hot and warm with the bodies of those just dead. The physician wrote

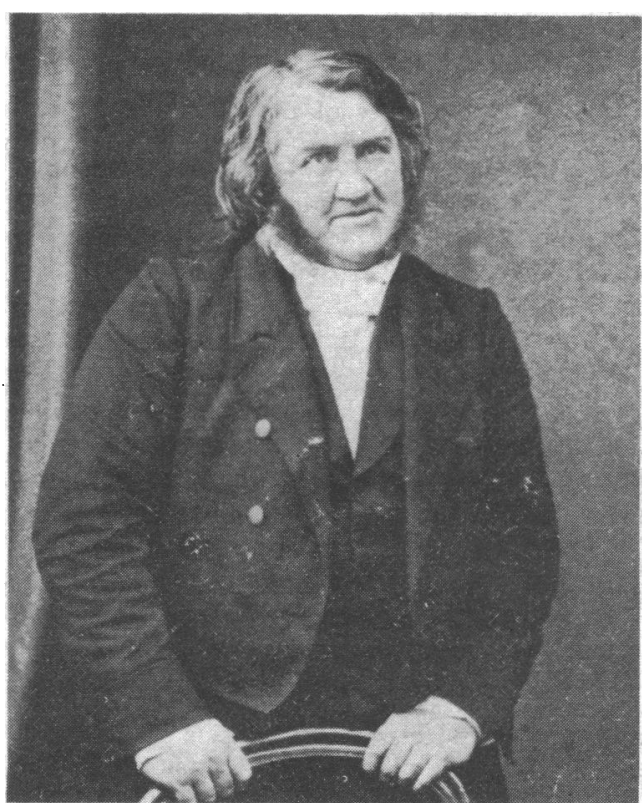

Sir James Y Simpson.

me today they had ... reduced last year the deaths to 10 percent by using means against contagion. Formerly they refused to believe in contagion-that is to say, they sacrificed the lives of 70 percent of the women delivered to their inhumane medical prejudices.

Is it not a terrible illustration of the extent to which medical prejudices will carry men? But at this moment in London perhaps still 80 percent of all those delivered are doomed (and doomed unnecessarily and cruelly) to agony and torture. That is they are (by their medical attendants too) sacrificed to suffer, as a fit-offering to the old medical prejudices regarding the propriety of pain. Both the Vienna and the London cases are illustrations of the same principledifferent in degree-but the same in essence.

To us in the North now such strange blindness looks most frightful inhumanity. Here all our ladies demand relief-and quite right. Two or three medical recusants are found, but not many; and their patients desert them."

\section{January 1851}

"Within the last hour I have for the first time looked over your chapter on an anaesthetic in labour. I would have done so sooner but I have latterly been taking little or no interest in the matter believing, as I do, it is now quite a settled question, and will be so in London also in the course of 10 or 20 years."

\section{? October 1851}

"Now as to your midwifery case where you used chloroform and applied the forceps. ... I I have not your letter beside me and have forgot the particulars, but I recalled the principal point of the spasms. ... Were these spasms and their effect any argument against anaesthesia in midwifery ? You think so. I don't.

I know they form no argument for they were undoubtedly the result of your abuse of the chloroform; or rather, I should say; they merely indicate that you were far too little acquainted with the use of it to know how to administer it properly. ... I am sure of this that no first year's student who has seen chloroform used properly in the surgical theatre or in midwifery would have met with such a contretemps as you describe. The simple mere fact was you did not give the patient enough chloroform.

Every student and surgeon's draper knows that the existence of such spasms merely shows that the patient is not yet sufficiently anaesthetised-that he or she must get a larger dose, and that it would be in the highest degree absurd to begin an operation till the patient's sleep is deeper. This is all so fully known here and I believe elsewhere by every one who has any knowledge at all of chloroform that your remarks only prove what $I$ have often thought and said: that its use in the relief of human suffering is delayed greatly in London by the sheer ignorance of the mode of using it which the London practitioners labour under. And this ignorance they doggedly refuse to rectify. 
Time will mend all this. Yesterday was the fourth anniversary of the first use of chloroform and I rejoice and feel thankful when I reflect on the amount of human suffering and agony which it has already saved in every quarter of the world. While, of course, I lament also that medical men still obstinately refuse to alleviate pain with it-merely in consequence of professional prejudice or professional apathy. Time will speedily cure this. The new race of medical men coming from schools and hospitals where they see it daily used will force their older brethren to its employment, whether they have hatreds and prejudices or not.

When at Banff two or three weeks ago I found the houses and the rooms all lighted with gas. On further inquiry I found they get their gas coals from Newcastle. But they are as far from Newcastle as you in London are. Yet here the community of a small village are several years in advance in civilisation to the inhabitants of the metropolis of England. The fact struck me at the time as a full ansiwer to your old observation that it was the distance and expense of the coal that kept you in London so far behind the march of most poor Scotch villages in this respect. No, no, it is not the distance of Newcastle, but the innate aversion to change and improvement which exists in the London mind. Rather, let my fellow men and women go on shrieking in pain and agony than ask one to change and learn aught new! Such, I fear, is the state of mind of many.

How are your London classes this session? Ours here are fuller even than last year in despite of all the attacks of the Lancet and your Dr [Robert] Lee. This winter I have begun the course with the physiology of reproduction. . . . I have written this at 4 am with my eyes half shutting, and I am not sure it is readable even."

Ramsbotham to Simpson, 23 January 1852

"You say the contretemps that I met with arose entirely from my abuse of the chloroform, from my ignorance of the mode of using it. It was administered not by myself, but by a gentleman who professed to understand how to do it and had often used it for surgical purposes.

.. For I never doubted the fact of relief from suffering, my only doubts regard the immunity from danger."

\section{Simpson to Ramsbotham, 21 April 1852}

"I have been up all night with a Manchester lady who has been chloroformed for two or three hours, and I write while waiting for my carriage. I have been reading at her bedside a paper on chloroform in labour sent to me this morning by $\mathrm{Dr}$ [Thomas E] Beattie of Dublin, and published in the last number of the Dublin Medical Press -with opinions very different from yours, and the London folks at large.

Every day I become more and more delighted with [chloroform] in midwifery, and I do sometimes wonder how our grandchildren will wonder at the opposition offered to it now. The other day I happened to look at Macaulay's chapter on the prejudices of the public mind during the Charles' times, or at least upon what we consider their prejudices now. He mentions how angry the London aristocracy and people were at Lord Stafford being simply beheaded without (as was the London custom) being first 'disemboweled alive,' and his bowels burned before the eyes of the half dead and tortured man. One shudders nowadays at the cruelty of such thoughts and doings. But the London doctors (many) still insist on the 'disembowelling' of every poor suffering mother during labour, when they know or should know it is totally unnecessary, and simply an act of cruelty at being unnecessary. Won't our descendents shudder at the idea of such things being systematically perpetrated by their medical forefathers ? From my inmost heart I believe they will."

\section{Ramsbotham to Simpson, 25 September 1852}

"I am quite as obstinate regarding chloroform as ever and in our department of the profession the practice certainly is not gaining ground in London."

\section{Simpson to Ramsbotham, 9 October 1852}

"I was glad to see your handwriting again. But still the old monomania about chloroform. I am sure that betimes you will look back ... upon your logic of prejudice, and be astonished that you could ever have used such puerile nonsequiturs.

Perhaps I will have the pleasure of shaking hands with you . . . the 1st of next month as I am to be in London for a few hours to deliver one of your great folks who wishes chloroform but who cannot get down to Edinburgh for her confinement.

I believe you are quite wrong in believing the use of chloroform is not extending in London. We have here research firms manufacturing it on the large scale. One of these firms tells me that weekly for some time they have shipped off each ... . one hundred pounds of it to one single drug house in London. Dr James Reid has been here for a few days. He tells me that Dr [Charles] Locock uses it occasionally. ... He (Dr Reid) does so also.

Be assured the London accoucheurs will betimes use it as freely and successfully as we all do it here. The more I see of it the more only do I wonder that you and Dr Lee should still persist in asking your patients to shriek and suffer in deference merely to your professional prejudices. Yesterday I was reading a letter from Dr Have [ ?] describing a public slave-whipping scene in New Orleans where a poor shrieking girl had a series of horrid lashes inflicted to serve merely the temper and prejudices of her master. And while the doctor gave a most heartrending account of her agonies he adds that what struck him as worst of all was all the other masters maintaining that this inhuman and cruel practice of theirs was the only safe practice with slaves, just as on equally untenable grounds you will with your pen maintain that the shrieking of patients in labour is the only safe practice for them. To my mind and heart, the one doctrine does not appear less shocking at this time of day than does the other."

\section{Ramsbotham to Simpson, 29 November 1852}

"I have already said that before I could sanction etherisation in labour I must be fully satisfied of its perfect safety. Time and experience must determine this point, and no one would be more ready to adopt the practice than myself, provided that were satisfactorily established. But I really cannot see the least analogy between flogging female slaves and refusing to exhibit a poisonous gas for the purpose of removing the pains of labour. The one suffering is a cruelty inflicted by man, the other an ordinance of the Deity. And it appears to me that such a mode of argument upon the subject is just so much waste of words."

Simpson to Ramsbotham, 10 August 1853

"Will you be so disloyal as to abuse chloroform now that the Queen has taken it (and sent me too a kind message about it).

I calculated years ago that if it was pretty generally acknowledged in London 10 years after its introduction it would be the most that could be expected from a body of practitioners so conservative and (let me add) so curiously prejudiced as London doctors usually are. Perhaps the example of the Queen will shorten this period. For the sake of your tortured woman may it be so!"

\section{Ramsbotham to Simpson, [12 or 13 August 1853]}

"You ask me whether I shall be so disloyal as to continue to abuse chloroform now that the Queen has taken it and say you think this example will shorten the period of its general introduction among us. There is no doubt in my mind that many women will desire to follow this example who would have been contented to have children as it would seem Nature intended they should, provided that example had not been set them. And that thus its use will become more general, whether for good or evil still, in my opinion, remains to be proved. You will not be surprised to hear from me that I think she should have been dissuaded from it.

It appears to me that the medical advisors on that occasion have placed themselves rather in a dilemma. They either considered its exhibition dangerous or they did not. If they did not, why should they have applied to a physician to superintend it who was not attached to the medical staff but who has paid particular attention to the effects of the drug? Why did not one of the regular attendents exhibit it himself? This very fact of their calling upon Dr [John] Snow . . . is the strongest possible proof that they considered they were running some risk. And in my humble estimation they were not warranted in increasing the ordinary risk in the most minute degree. ... .

I have always told you that prejudice had no part in my objections, and I have therefore made its effects in labour the subject of careful personal observation. I have come to the conclusion that it is quite possible to give it in such a modified degree as will quickly relieve the suffering without annulling consciousness, and so far one of my chief objections, if not the chief, is obviated. But I have still great doubt whether we can always calculate upon exhibiting a dose such as will in different constitutions invariably produce just the effect we desire and no more. Teach us to do that and the practice will not meet with any more opposition from me. It was against the thorough annihilation for the time of mental consciousness, as of corporeal sensation, that my remarks have always been directed."

Simpson to Ramsbotham, 15 August 1853

"I am glad to see you are going to alter your opinions about 
chloroform in labour. But you will prove-if you all change-my old prognosis to be wrong, that 'it would not reach London for 10 or 20 years.'

The ladies themselves will keep medical men right about the proper quantity in parturition. I had a case this morning [where] the lady had come a long distance for chloroform. I gave her small doses at first, but she cried out for "more and more" till she was asleep. One of your high English folks has come here to have it next month because in London they would not give her enough! She was a patient of Rigby's during her two last labours and was here in her first. Yesterday I got a patient from ... Spain who has come over for it.

I have got nearly worn out with work just now and dream of running away to Northumberland to study the Roman wall for some days."

When chloroform was administered to Queen Victoria on 7 April 1853, at the birth of Prince Leopold, it gave a "seal of approval" to the practice and terminated most opposition to the use of obstetric anaesthesia. For those who continued to object to its use on religious grounds, surely the fact that the daughter of the Archbishop of Canterbury received chloroform during childbirth later that year was not overlooked. Nevertheless, a lingering conservatism like that maintained by $\mathrm{Dr}$ Ramsbotham probably continued among some physicians.

In the third edition of his Principles and Practice of Obstetric Medicine and Surgery, published in 1851, Ramsbotham warned the profession that "some degree of hazard must always attend" the use of chloroform and "no medical man is justified in increasing, even to the least amount, the dangers that hover around a parturient woman." 8 From Simpson's 1853 correspondence one gets the impression that $\mathrm{Dr}$ Ramsbotham was "going to alter" this view. If indeed he did, it certainly was not in any decisive way because in the fourth edition of his text, appearing in 1856, Ramsbotham concludes his chapter on anaesthesia in labour with the emphatic declaration that, "I have not seen the least reason to alter the opinions . . . that before anaesthetics can be introduced for the relief of ordinary pains of childbirth it must be proved incontestably that they are invariably safe both to the mother and her infant." "

In November 1856 Dr Ramsbotham delivered the opening address to the Harveian Society. It was a somewhat imprecise, rambling oratory on "Suggestions in Reference to the Means of Advancing Medical Science," extolling the major contributions of medical science and emphasising the progress made in recent times. Not once throughout the talk could Ramsbotham bring himself to acknowledge chloroform anaesthesia, or its discoverer, by name. However, when he broached the subject of the "adaptation of medicinal substances to the healing art," including "some new drugs before unknown," Ramsbotham was quick "to offer his opinion that medical men are not in general sufficiently attentive to the forms in which they administer their drugs, and to the vehicles in which they convey them." ${ }^{10}$

The fifth edition of Dr Ramsbotham's work was published in 1867 , one year before he died. Graciously inscribed from "his sincere friend," the volume was dedicated to "Sir James Y Simpson, Bart, whose indefatigable exertions in the cause of science, and successful efforts to alleviate human suffering have rendered his name famous throughout the world." In this work Ramsbotham reprinted his chapter on anaesthesia in labour exactly as it was published 11 years previously, but to it he then added:

"Experience has fortunately proved that the gloomy anticipations, which I had formed respecting the danger universally attending the administration of anaesthetics, have turned out to be, in some degree, fallacious; or at least it is not so great as I feared it would be; for the casualties that have resulted from their use during that period have been astonishingly few. And I am pleased to have the opportunity of confessing the value of this drug, in those cases where ... I have advised its exhibition."11

It had been 20 years since Simpson introduced chloroform anaesthesia in obstetrics. Conservative, and honourable, Dr Ramsbotham wanted to preserve "on record what my feelings
... formerly were, as well as the change that further experience has produced in my opinions."12

I gratefully acknowledge the assistance received from librarians, especially Joan P S Ferguson, Royal College of Physicians, Edinburgh; Robin Price, Wellcome Institute for the History of Medicine, London; Dorothy U Wardle, Royal College of Surgeons, Edinburgh; and Richard J Wolfe, Francis A Countway Library of Medicine, Boston.

\section{Notes}

1 Munro Kerr JM, Johnstone RW, Phillips MH, Historical Review of British Obstetrics and Gynaecology, 1850-1950. Edinburgh: E and S Livingstone, $1954 ; 227$. A fine review of the subject, see particularly "Ether and Chloroform," pp 226-31.

2 Biographies that should be consulted are Duns J, Memoir of Sir fames $Y$ Simpson. Edinburgh: Edmonston and Douglas, 1873; Gordon $\mathbf{H}$ Laing, Sir Fames $Y$ Simpson and Chloroform. London: T Fisher Unwin, 1897; Blantyre Simpson Eve, Sir fames $Y$ Simpson. Edinburgh: Oliphant Anderson and Ferrier, 1896; and Simpson Myrtle, Simpson the Obstetrician; A Biography. London: Victor Gollancz, 1972. Histories of the subject include the recently published work by Youngson AJ, The Scientific Revolution in Victorian Medicine. London: Croom Helm, 1979; The Edinburgh Medicalfournal, "James Young Simpson Number," June 1911, New Ser 6; and Duffy John, Anglo-American reaction to obstetrical anesthesia. Bulletin of the History of Medicine, $1964 ; 38: 32-44$. See also The Works of Sir Fames Young Simpson, 2. Sir W G Simpson, ed. Edinburgh: Adams and Charles Black, 1871. For an interesting article on some Simpson letters, see Gaskell E, Three letters of Sir James Young Simpson, British Medical fournal 1970;ii:414-6.

3 Gordon H Laing. Sir fames $Y$ Simpson and Chloroform. London: $T$ Fisher Unwin, 1897:134.

4 Obituary, British Medical fournal 18 July 1868, 62; Dictionary of National Biography. London $1896 ; 47,265$. Additional biographical information appears in William Munk, Lives of the Fellows of the Royal College of Physicians of London, 1826-1925. Brown GH, comp. London, 1955:37. The first two editions of Ramsbotham's book were dedicated to his father, who had also published works on midwifery and had been consulting physician to the Royal Maternity Charity and lecturer on obstetric medicine at the London Hospital.

5 Letter from Simpson to Ramsbotham, 28 November 1853.

${ }^{6}$ Gordon $\mathrm{H}$ Laing. Sir fames $Y$ Simpson and Chloroform. London: T Fisher Unwin, 1897:164.

${ }^{7}$ Letter is in the collections of the Royal College of Surgeons, Edinburgh.

${ }^{8}$ Ramsbotham Francis H. Principles and Practice of Obstetric Medicine. London: John Churchill, $1851: 183$.

${ }^{9}$ Ramsbotham Francis H. Principles and Practice of Obstetric Medicine. London: John Churchill, 1856:192.

10 Ramsbotham Francis H. Suggestions in Reference to the Means of Advancing Medical Service... delivered before the members of the Harveian Society on 6 November 1856. London: John Churchill, 1856:19-20.

11 Ramsbotham Francis H. Principles and Practice of Obstetric Medicine. London: John Churchill, 1867:197.

12 Dr Ramsbotham's book was also published in the United States (Philadelphia), the first edition appearing in 1842. The initial discussion of "anaesthesia in labour" appeared in the British third edition (1851) and was reprinted as a "supplement" in the American sixth edition (also 1851). In 1855, however, when a new American edition was published, with notes and additions by William V Keating, Ramsbotham's 1851 text was reprinted with a seven-page essay added repudiating the author's point of view: "It is with utmost diffidence, after the perusal of the author's powerful and eloquent phillippic against anaesthesia that we presume to differ from some of the views there laid down. . .." (p 197).

A note on the source of the collection

While we cannot be certain exactly how the library obtained the Ramsbotham-Simpson collection, a reasonable explanation is possible. John Shaw Billings, who as director of the library of the Surgeon General's Office from 1865 to 1895 greatly increased the holdings of the institution and, for all practical purposes, made it a national medical library, became good friends with Thomas Windsor, of Manchester, a physician, bibliographer, and book collector. Dr Windsor had retired from active practice in 1878 , at the age of 47 , and devoted an ever-increasing amount of time to his bibliophilic interests. In the process, and probably with more than just a little encouragement from Dr Billings, Windsor became very interested in the library in Washington, expressing this concern through frequent donations of books and manuscripts. According to Library records, the Ramsbotham-Simpson material was accessioned on 28 May 1890, a time when Dr Windsor's generous contributions were being received regularly. (For an article on Windsor and the library, see Schullian Dorothy $M$. Thomas Windsor, benefactor of the Army Medical Library. Bulletin of the Medical Library Association 1950;38:135-44; the development of the library is outlined in Waserman Manfred. Historical chronology and selected bibliography relating to the National Library of Medicine. Bulletin of the Medical Library Association, 1972 ;60:551-8.) 